\title{
Investigation of Low-Temperature Lean Combustion Characteristics in Power Plants with External Heating of Components
}

\author{
Bachev N.L., Shilova A.A., Matyunin O.O., Betinskaya O.A. \\ Perm National Research Polytechnic University \\ Perm, Russian Federation
}

\begin{abstract}
An integral part of any open-type gas turbine plant is a low-emission combustion chamber, which is usually two-zone and cooled. One of the ways to reduce emission of harmful substances is organizing low-emission low-temperature lean combustion with external heating of components. This paper investigates the effect of external heating of air and fuel gas on expansion of the lower combustion limit and stable flame position in a single-zone uncooled combustion chamber of a microgas turbine power plant. Stable position of the flame front in combustion chambers of this type mainly depends on the ratio between the average flow rate of the combustible-air mixture and the rate of turbulent combustion. This ratio depends on thermal, gas-dynamic, thermochemical and geometric factors. The purpose of this work is to substantiate the possibility of using the relative flow rate as a generalized characteristic. This goal was achieved in processing a large amount of published experimental data and numerical modeling of low-temperature combustion of lean mixtures. The most significant research result is determination of the range of relative flow rate $\left(g_{k}=0.3 \ldots 3.5 \cdot 10^{-4} \mathrm{~kg} / \mathrm{s} \cdot \mathrm{N}\right)$, at which it is possible to ensure stable flame position in a single-zone combustion chamber. Significance of the obtained results lies in the fact that using the relative flow rate makes it possible to quickly determine and analyze the geometric and gas-dynamic parameters and characteristics of turbulent combustion in combustion chambers of micro-gas turbine power plants.
\end{abstract}

Keywords: low-temperature lean combustion, external heating of components, stable position of turbulent flame, relative flow rate.

DOI: https://doi.org/10.52254/1857-0070.2021.2-50.11

UDC: 665.612 .2

\section{Studiul caracteristicilor combustiei slabe la temperatură scăzută în centralele electrice cu încălzire externă a componentelor \\ Bacev N.L., Șilova A.A., Matiunin O.O., Betinscaia O.A. \\ Universitatea Națională de cercetare politehnică din Perm, Perm, Federația Rusă}

Rezumat. O parte componentă a unei centrale cu turbină cu gaz deschisă este o cameră de combustie, care este realizată de obicei în două zone și răcită. Această lucrare investighează efectul încălzirii externe a aerului și a gazului combustibil asupra extinderii limitei inferioare de ardere și a poziției stabile a flăcării într-o cameră de combustie fără răcire într-o singură zonă a unei centrale cu turbină cu gaz. Poziția stabilă a frontului de flacără în camerele de ardere de acest tip depinde în principal de raportul dintre debitul mediu al amestecului de aer combustibil și rata de ardere. Acest raport depinde de factorii termici, gazodinamici, termochimici şi geometrici. Scopul acestei lucrări este de a fundamenta posibilitatea utilizării unei caracteristici generalizate - debitul relativ, care face posibilă luarea în considerare a influenței parametrilor geometrici, termodinamici și a debitului asupra stabilității la combustie. Acest obiectiv a fost atins în procesul de procesare a unei cantități mari de date publicate și de calcul numeric al arderii la temperatură scăzută a amestecurilor slabe la valori ridicate ale coeficientului de aer în exces. Cel mai semnificativ rezultat al cercetării este determinarea intervalului debitului relativ $(\mathrm{gk}=0,3$ $\ldots 3,5 \cdot 10-4 \mathrm{~kg} / \mathrm{s} \cdot \mathrm{N})$, care poate asigura o poziție stabilă a flăcării într-o cameră de ardere cu o singură zonă. Semnificația rezultatelor obținute constă în faptul că utilizarea debitului relativ face posibilă determinarea și analiza rapidă a parametrilor și caracteristicilor geometrice și gazodinamice și a caracteristicilor arderii turbulente în camerele de ardere ale centralelor cu turbină cu gaz.

Cuvinte-cheie: combustie slabă la temperatură scăzută, încălzirea externă a componentelor, poziția stabilă a flăcării turbulente, debitul relativ.

Исследование характеристик низкотемпературного бедного горения в энергоустановках с внешним подогревом компонентов

Бачев Н.Л., Шилова А.А., Матюнин О.О., Бетинская О.А.

Пермский национальный исследовательский политехнический университет,

Пермь, Российская Федерация

Аннотация. Составной частью газотурбинной установки открытого типа является камера сгорания, которая обычно выполняется двухзонной и охлаждаемой. В первичной зоне обеспечивается устойчивое

(C) Бачев Н.Л., Шилова А.А.

Матюнин О.О., Бетинская О.А., 2021 
горение при высокой температуре, а в зоне разбавления происходит подготовка рабочего тела для подачи на турбину. Одним из способов снижения эмиссии вредных веществ является организация низкоэмиссионного низкотемпературного бедного горения при внешнем подогреве компонентов в теплообменных аппаратах отработанными на турбине газами. В данной работе исследуется влияние внешнего подогрева воздуха и топливного газа на расширение нижнего предела горения и стабильное положение пламени в однозонной неохлаждаемой камере сгорания газотурбинной энергоустановки. Устойчивое положение фронта пламени в камерах сгорания такого типа в основном зависит от соотношения между среднерасходной скоростью горюче-воздушной смеси и скоростью горения. Это соотношение зависит от тепловых, газодинамических, термохимических и геометрических факторов. Целью данной работы является обоснование возможности использования обобщенной характеристики - относительная расходонапряженность, которая позволяет учесть влияние геометрических, расходных и термодинамических параметров на устойчивость горения. Поставленная цель была достигнута в процессе обработки большого количества опубликованных данных и численного расчета низкотемпературного горения бедных смесей при больших значениях коэффициента избытка воздуха. Наиболее значимым результатом исследований является определение диапазона относительной расходонапряженности $\left(g_{k}=0.3 \ldots 3.5 \cdot 10^{-4}\right.$ кг/c·H $)$, при котором можно обеспечить стабильное положение пламени в однозонной камере сгорания. Значимость полученных результатов состоит в том, что использование относительной расходонапряженности позволяет оперативно определять и анализировать геометрические и газодинамические параметры и характеристики турбулентного горения в камерах сгорания газотурбинных энергоустановках. Предложенная методика была опробирована на установках полезной мощностью 200 и 400 кВт.

Ключевые слова: низкотемпературное бедное горение, внешний подогрев компонентов, устойчивое положение турбулентного пламени, относительная расходонапряженность.

\section{ВВЕДЕНИЕ}

Разработка газотурбинных энергоустановок с низким выбросом вредных веществ попрежнему остается весьма актуальной задачей [1]. В данной работе для снижения эмиссии вредных веществ предлагается использовать низкотемпературное горение обедненной смеси с коэффициентами избытка воздуха в области нижнего предела воспламенения.

Обзор работ показывает, что по влиянию параметров подачи на пределы горения в основном имеются экспериментальные данные, полученные для стандартных топливных газов и их смесей при горении в воздухе. В работах $[2,3,4,5,6]$ экспериментально показана линейная зависимость верхнего и нижнего пределов горения от начальной температуры для широкого диапазона топливных композиций. Работы [7, 8, 9] посвящены экспериментальному изучению влияния начального давления на нижний и верхний пределы горения, причем в разных работах получены разные данные по влиянию давления. В [7] указывается на логарифмическую зависимость, в [8] - на квадратичную зависимость, а в [9] на линейную зависимость верхнего предела горения от начального давления. Во всех работах отмечается, что нижний предел горения практически не зависит от начального давления. Известны также расчетноэкспериментальные исследования по влиянию параметров подачи и состава компонен- тов на нормальную скорость горения. В работах $[10,11,12,13,14,15,16,17,18]$ экспериментально изучалось влияние давления до 5,0 МПа и температуры до 900 К на входе в камеру сгорания на нормальную скорость горения для различных топливных композиций. В $[14,15,16,17]$ предлагаются корреляционные эмпирические зависимости нормальной скорости горения от параметров подачи топливного газа и воздуха.

В работах [19, 20, 21, 22, 23] приводятся сравнения экспериментальных данных и результатов численного моделирования по нормальной скорости горения. Отмечается, что при численном моделировании зависимость нормальной скорости горения от температуры подачи получается более сильной, чем в экспериментальных исследованиях. Особо следует выделить работу [21], посвященную экспериментальному исследованию горения топливной композиции синтезгаз+воздух в камерах сгорания газотурбинных установок при изменении давления подачи до 1.5 МПа и температуры горючевоздушной смеси до $600 \mathrm{~K}$.

В работах $[24,25]$ дается анализ ранее разработанных теорий скорости турбулентного горения и генерации тербулентности пламенем и указывается на необходимость экспериментальной проверки существующих теорий.

Таким образом, обзор опубликованных работ показал, что все расчетные и экспери- 
ментальные исследования были направлены на изучение вопросов по влиянию параметров подачи воздуха и топливного газа на пределы воспламенения и величину нормальной скорости горения. Отличительной особенностью данной работы является изучение газодинамических параметров и характеристик горения для выработки критерия стабильного положения пламени при малоэмиссионном низкотемпературном бедном горении с внешним подогревом компонентов. По результатам проведенных исследований получен диапазон относительной расходонапряженности $\left(g_{k}=(0.3 \ldots 3.5) \cdot 10^{-4}\right.$ кг/c·H), при котором можно обеспечить стабильное положение пламени в однозонной камере сгорания.

\section{ГАЗОДИНАМИЧЕСКАЯ МОДЕЛЬ ТУРБУЛЕНТНОГО ГОРЕНИЯ С}

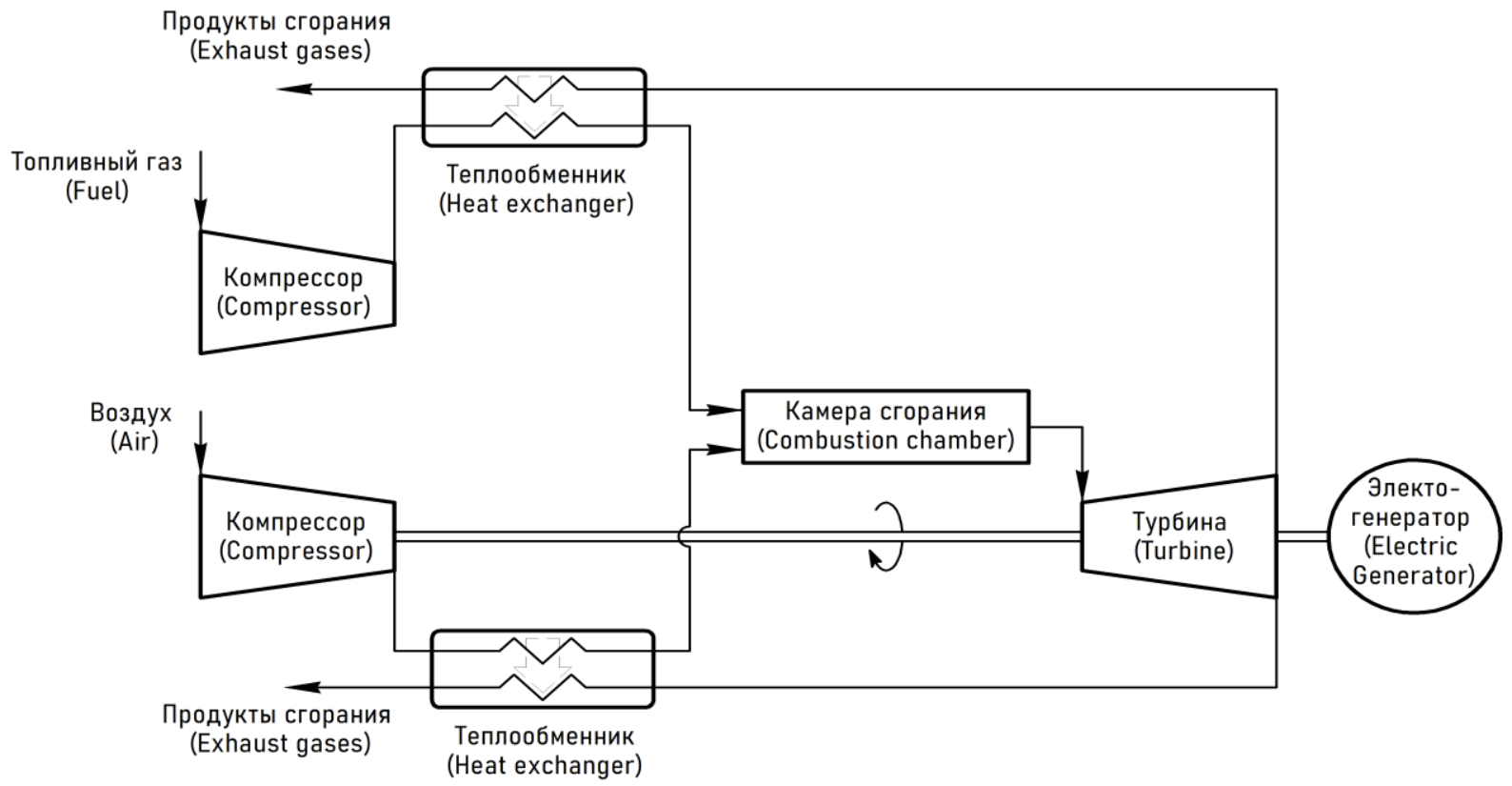

Рис. 1. Принципиальная схема МГТЭУ с внешним подогревом компонентов. ${ }^{1}$

Коэффициент избытка воздуха на нижнем пределе:

$$
\alpha_{L}=\frac{1}{K_{m 0}} \cdot \frac{\rho_{o x}}{\rho_{f}} \cdot \frac{100-L_{L}}{L_{L}},
$$

где $L_{L}$ - нижний предел горения топливного газа в об. \%; $K_{m 0}$ - массовое стехиометрическое соотношение компонентов.

$$
\begin{aligned}
& { }^{1} \text { Appendix } 1 \\
& \text { ляюгся но уравнениям: } \\
& \qquad \rho_{o x}=\frac{P_{i n}}{R_{o x} \cdot T_{o x}^{i n}}
\end{aligned}
$$

\section{ВНЕШНИМ ПОДОГРЕВОМ КОМПОНЕНТОВ}

Известно, что с увеличением температуры воздуха и топливного газа на входе в КС изменяются концентрационные пределы горения. Температуры подогрева воздуха и топливного газа по-разному влияют на показатели внутрикамерного рабочего процесса и газотурбинной установки в целом. Подогрев воздуха сужает область устойчивого горения в КС, но увеличивает эффективность ГТУ. Подогрев топливного газа расширяет область устойчивого горения в КС и сильно сдвигает нижний предел горения в сторону бедных смесей, не влияя практически на эффективность установки.

Принципиальная схема МГТЭУ с внешним подогревом компонентов и однозонной КС представлена на рисунке 1. 
Нижние пределы горения при подогреве компонентов ${ }^{3}$.

\begin{tabular}{|c|c|c|c|c|c|}
\hline \multicolumn{6}{|c|}{$\alpha_{L}$} \\
\hline \multirow{2}{*}{$T_{o x}^{\text {in }}, \mathrm{K}$} & \multicolumn{5}{|c|}{$T_{f}^{\text {in }}, \mathrm{K}$} \\
\cline { 2 - 6 } & 288 & 400 & 600 & 800 & 1000 \\
\hline 288 & 1.9 & 3.0 & 5.5 & 9.4 & 16.2 \\
\hline 400 & 1.4 & 2.1 & 3.9 & 6.7 & 11.6 \\
\hline 600 & 0.9 & 1.4 & 2.6 & 4.5 & 7.7 \\
\hline 800 & 0.7 & 1.1 & 1.9 & 3.4 & 5.8 \\
\hline 1000 & 0.5 & 0.8 & 1.6 & 2.7 & 4.6 \\
\hline
\end{tabular}

На рисунке 2 приведены графические зависимости $\alpha_{L}=f\left(T_{o x}^{i n}, T_{f}^{i n}\right)$.

Анализ данных на рисунке 2 показывает, что температуры подогрева компонентов поразному влияют на нижний предел горения. С

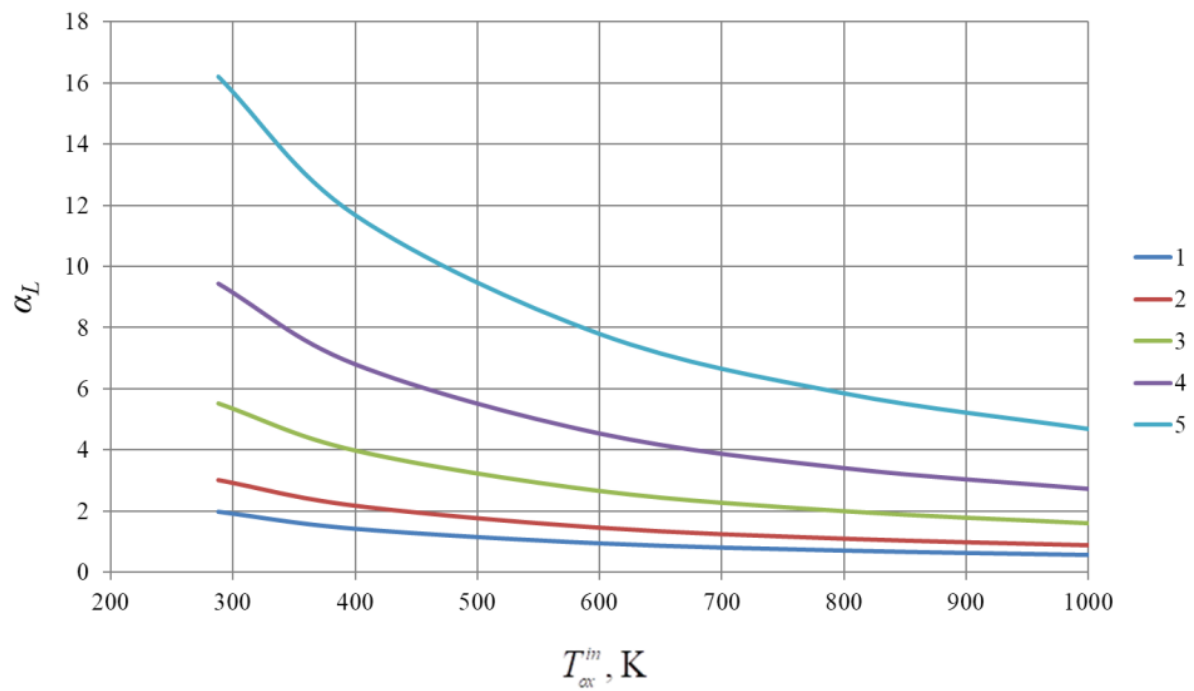

$1-T_{f}^{i n}=288 \mathrm{~K}, 2-T_{f}^{i n}=400 \mathrm{~K}, 3-T_{f}^{i n}=600 \mathrm{~K}, 4-T_{f}^{i n}=800 \mathrm{~K}, 5-T_{f}^{i n}=1000 \mathrm{~K}$.

Рис. 2. Нижние пределы горения при подогреве компонентов. ${ }^{4}$

Температура ГВС на нижнем пределе горения может быть определена из уравнения теплового баланса для смеси:

$$
T_{F A M}=\frac{\alpha_{L} \cdot K_{m 0} \cdot c_{p o x} \cdot T_{o x}^{i n}+c_{p f} \cdot T_{f}^{i n}}{\left(1+\alpha_{L} \cdot K_{m 0}\right) \cdot c_{p F A M}} .
$$

Удельные теплоемкости воздуха и топ2,3,4 Appendix 1 зисимости от температуры nх пидачи в nе ипределяются по линейным зависимостям, полученным методом наименьших квадратов при обработке табличных данных: увеличением $T_{o x}^{\text {in }}$ пределы $\alpha_{L}$ уменьшаются, а с увеличением $T_{f}^{\text {in }}$ пределы $\alpha_{L}$ резко возрастают. 
Результаты расчета $T_{F A M}$ при разных темле (2) представлены в таблице 2. пературах подогрева компонентов по форму-

Таблица $2^{5}$.

Температура ГВС при подогреве компонентов ${ }^{6}$.

\begin{tabular}{|c|c|c|c|c|c|}
\hline \multicolumn{5}{|c|}{$T_{F A M}, \mathrm{~K}$} \\
\hline \multirow{2}{*}{$T_{o x}^{i n}, \mathrm{~K}$} & \multicolumn{5}{|c|}{$T_{f}^{\text {in }}, \mathrm{K}$} \\
\cline { 2 - 6 } & 288 & 400 & 600 & 800 & 1000 \\
\hline 288 & 288.0 & 293.2 & 298.1 & 299.9 & 299.3 \\
\hline 400 & 391.0 & 400.0 & 408.7 & 412.5 & 412.9 \\
\hline 600 & 565.0 & 582.3 & 600.0 & 608.9 & 612.3 \\
\hline 800 & 728.4 & 755.5 & 784.2 & 800.0 & 807.9 \\
\hline 1000 & 882.9 & 921.2 & 962.4 & 986.3 & 1000.0 \\
\hline
\end{tabular}

На рисунке 3 представлены графические зависимости $T_{F A M}=f\left(T_{o x}^{i n}, T_{f}^{i n}\right)$.

Анализ данных на рисунке 3 показывает, что температура ГВС практически не зависит от температуры подачи горючего, а в основном определяется температурой подачи окислителя.

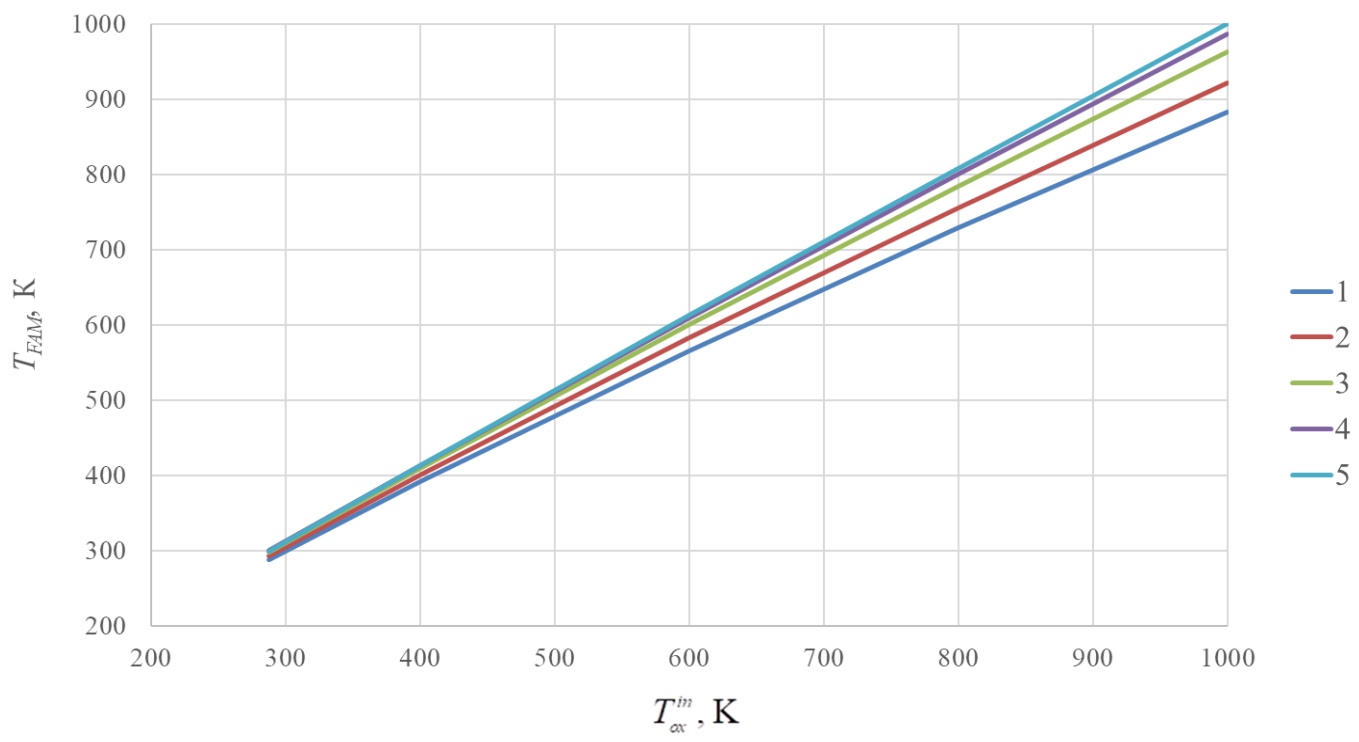

$1-T_{f}^{i n}=288 \mathrm{~K}, 2-T_{f}^{i n}=400 \mathrm{~K}, 3-T_{f}^{i n}=600 \mathrm{~K}, 4-T_{f}^{i n}=800 \mathrm{~K}, 5-T_{f}^{i n}=1000 \mathrm{~K}$.

Рис. 3. Температура ГВС при подогреве компонентов. ${ }^{7}$

Из уравнения энергетического баланса, записанного для КС, можно определить тем${ }_{5,6,7}$ Appendix 1 сгорания на нижнем преД

$$
T_{C P}=\frac{\alpha_{L} \cdot K_{m 0} \cdot c_{p o x} \cdot T_{o x}^{i n}+c_{p f} \cdot T_{f}^{i n}+H u \cdot \eta_{c}}{\left(1+\alpha_{L} \cdot K_{m 0}\right) \cdot c_{p C P}},
$$

где $H u, \eta_{c}-$ теплопроизводительность и полнота сгорания топливного газа.
Удельная теплоемкость ПС на нижнем пределе горения может быть определена по квадратичной зависимости, полученной по результатам термодинамического расчета горения:

$$
c_{p C P}=6 \cdot \alpha_{L}^{2}-61.1 \cdot \alpha_{L}+1356.6 .
$$


Результаты расчета $T_{C P}$ по формуле (3) нентов представлены в таблице 3. при разных температурах подогрева компо-

Таблица $3^{8}$.

Температура ПС на нижнем пределе горения9 .

\begin{tabular}{|c|c|c|c|c|c|}
\hline \multicolumn{5}{|c|}{$T_{C P}, \mathrm{~K}$} \\
\hline \multirow{2}{*}{$T_{o x}^{\text {in }}, \mathrm{K}$} & \multicolumn{5}{|c|}{$T_{f}^{\text {in }}, \mathrm{K}$} \\
\cline { 2 - 6 } & 288 & 400 & 600 & 800 & 1000 \\
\hline 288 & 1343 & 1001 & 678 & 461 & 246 \\
\hline 400 & 1740 & 1359 & 940 & 696 & 460 \\
\hline 600 & 2453 & 1983 & 1385 & 1071 & 825 \\
\hline 800 & 3176 & 2599 & 1824 & 1427 & 1159 \\
\hline 1000 & 3923 & 3207 & 2264 & 1782 & 1477 \\
\hline
\end{tabular}

На рисунке 4 представлены графические зависимости $T_{C P}=f\left(T_{o x}^{i n}, T_{f}^{i n}\right)$.

В МГТЭУ с неохлаждаемой турбиной целесообразно выбирать температуру рабочего тела на входе в турбину $T_{i n}^{t} \leq 1200 К$ для сохранения работоспособности неохлаждаемых элементов конструкции и увеличения ресурса работы энергоустановки в целом. По заштрихованной области на рисунке 4 можно определять потребные значения температур компонентов на входе в КС для обеспечения заданной температуры на входе в турбину.

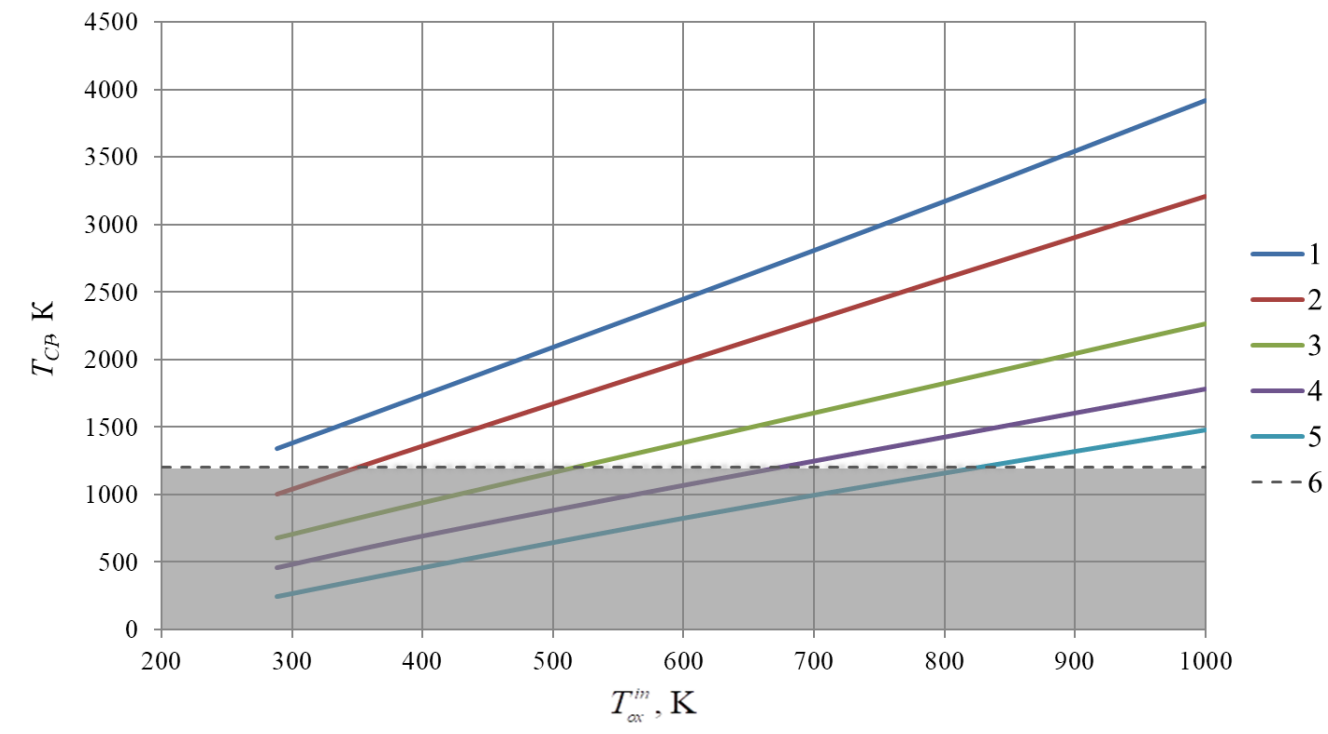

$1-T_{f}^{i n}=288 \mathrm{~K}, 2-T_{f}^{i n}=400 \mathrm{~K}, 3-T_{f}^{i n}=600 \mathrm{~K}, 4-T_{f}^{i n}=800 \mathrm{~K}, 5-T_{f}^{i n}=1000 \mathrm{~K}, 6-T_{t}^{i n}=1200 \mathrm{~K}$.

Рис. 4. Область низкотемпературного горения МГТЭУ. ${ }^{10}$

Среднерасходная скорость ГВС вдоль КС: ${ }_{8,9,10}$ Appendix 1

$$
W_{F A M}=\frac{4 \cdot\left(\dot{m}_{o x}+\dot{m}_{f}\right)}{\rho_{F A M} \cdot \pi \cdot d_{d}^{2}}
$$

где $d_{d}$ - диаметр КС.
Расходы рабочего тела $\dot{m}_{g}$ через турбину, окислителя $\dot{m}_{o x}$ и горючего $\dot{m}_{f}$ через КС определяются по следующим соотношениям:

$$
\begin{gathered}
\dot{m}_{g}=\frac{N_{n e t}}{L_{e f f}}, \\
\dot{m}_{f}=\frac{\dot{m}_{g}}{1+\alpha \cdot K_{m 0}},
\end{gathered}
$$




$$
\dot{m}_{o x}=\alpha \cdot K_{m 0} \cdot \dot{m}_{f},
$$

где $N_{\text {net }}, L_{\text {eff }}$ - полезная мощность и эффективная работа МГТЭУ.

Плотность ГВС определяется по уравнению состояния:

$$
\rho_{F A M}=\frac{P_{c h}}{R_{F A M} \cdot T_{F A M}} .
$$

Газовая постоянная ГВС:

$$
R_{F A M}=\frac{R_{0}}{M_{F A M}}
$$

где $R_{0}-$ универсальная газовая постоянная.

Молярная масса ГВС:

$$
M_{F A M}=\varphi \cdot M_{f}+(1-\varphi) \cdot M_{o x} .
$$

Нормальная скорость горения при стехиометрическом соотношении компонентов и произвольной температуре ГВС определяется по эмпирическому соотношению:

$$
U_{n 0}=0.502 \cdot 10^{-5} \frac{K_{m 0}}{14.7} \cdot T_{F A M}{ }^{2},
$$

где $K_{m 0}-$ стехиометрическое соотношение между воздухом и топливным газом.

Нормальную скорость горения с учетом давления в КС и состава ГВС вблизи нижнего предела предлагается определять по зависимости:

$$
U_{n}=U_{n 0} \cdot\left(\frac{P_{c h}}{P_{0}}\right)^{-0.2} \cdot \frac{\alpha_{L}-\alpha}{\alpha_{L}-1}
$$

где $P_{0}$ - стандартное давление; $P_{c h}$ - давление в КС; $\alpha$ - действительный коэффициент избытка воздуха в КС.

Турбулентная скорость горения определялась эмпирическому соотношению, которое учитывает турбулентность газового потока и дополнительно автотурбулизацию от пламени:

$$
U_{t}=\theta \cdot U_{n}+W_{F A M} \cdot \varepsilon
$$

где степень подогрева газа в КС равна:

$$
\theta=T_{C P} / T_{F A M}
$$

Интенсивность турбулентности $\varepsilon$ по данным экспериментальных исследований для камер сгорания без завихрителя $\varepsilon=0.03 \ldots 0.05$.

Скорость продуктов сгорания на выходе из КС:

$$
W_{C P}=\frac{4 \cdot\left(\dot{m}_{o x}+\dot{m}_{f}\right)}{\rho_{C P} \cdot \pi \cdot d_{d}^{2}},
$$

где $\rho_{C P}$ - плотность продуктов сгорания.

\section{АНАЛИЗ УСТОЙЧИВОСТИ ТУРБУЛЕНТНОГО ГОРЕНИЯ В КС МИКРОГАЗОТУРБИННЫХ ЭНЕРГОУСТАНОВОК}

Устойчивое положение турбулентного пламени в КС МГТЭУ в сильной степени зависит от соотношения среднерасходной скорости ГВС и скорости турбулентного горения. При подогреве топливного газа нижний предел горения сильно смещается в область больших значений $\alpha$. Сильно обедненная смесь предполагает увеличение расходов воздуха, что может привести к нарушению устойчивости пламени в КС заданной геометрии.

В однозонной КС тепловое состояние компонентов на входе в КС и их суммарный расход определяют расходную скорость ГВС через поперечное сечение камеры. Соотношение среднерасходной скорости ГВС и скорости турбулентного горения зависит от множества факторов, главными из которых являются: полезная мощность МГТЭУ; диаметр КС; температуры окислителя и горючего на входе в КС; давление в КС; коэффициент избытка воздуха; степень подогрева и интенсивность турбулентности газа в КС.

Обработка экспериментальных данных, полученных при горении бензиновоздушных смесей с различной начальной температурой, позволила построить экспериментальную зависимость $W_{\text {гвс }} / U_{t}=f\left(W_{\text {гвс }}\right)$ на режиме устойчивого горения, показанную на рисунке 5.

Анализ экспериментальных данных, использованных при получении кривой на рисунке 5, позволяет сделать вывод, что устойчивое горение углеводородных топлив в горелках атмосферного типа происходит при 
значениях относительной расходонапряженности:

$$
g_{k}=(0.3 \ldots 3.5) \cdot 10^{-4} \frac{\mathrm{K} \Gamma}{\mathrm{c} \cdot \mathrm{H}} .
$$

С целью изучения условий обеспечения устойчивого пламени и определения значений относительной расходонапряженности в КС МГТЭУ было проведено численное моделирование низкотемпературного бедного горения топливной композиции природный газ+воздух с использованием программного комплекса Flow Vision и пульсационной модели горения. Теплогазодинамические параметры при реализации численной модели с внешним подогревом компонентов до $800 \mathrm{~K}$ представлены в таблице 4.

На рисунке 6 представлено распределение интенсивности пламени возле смесительной головки при низкотемпературном бедном горении.

Анализ полей интенсивности горения на рисунке 6 показал, что при относительной расходонапряженности $g_{k}=0.7 \cdot 10^{-4} \mathrm{\kappa r} /(\mathrm{c} \cdot \mathrm{H})$ пламя имеет стабильное положение около смесительной головки и частично заходит внутрь полости форсунок. При температуре горения 1200 К конструктивные элементы КС не нуждаются в охлаждении. Температура внутри форсунок меньше, чем температура воспламенения, равная 923 К, поэтому горение внутри форсунок отсутствует.

В таблице 5 представлены теплогазодинамические параметры при использовании численной модели с внешним подогревом воздуха до 600 К и топливного газа до $800 \mathrm{~K}$.

На рисунке 7 представлено распределение интенсивности пламени возле смесительной головки при низкотемпературном бедном горении при внешнем подогреве компонентов воздуха до 600 К и топливного газа до $800 \mathrm{~K}$.

Анализ полей интенсивности горения на рисунке 7 показал, что при относительной расходонапряженности $g_{k}=0.8 \cdot 10^{-4} \mathrm{\kappa r} /(\mathrm{c} \cdot \mathrm{H})$ пламя имеет стабильное положение возле смесительной головки и не заходит внутрь форсунок. При температуре горения $984 \mathrm{~K}$ конструктивные элементы КС не нуждаются в охлаждении.

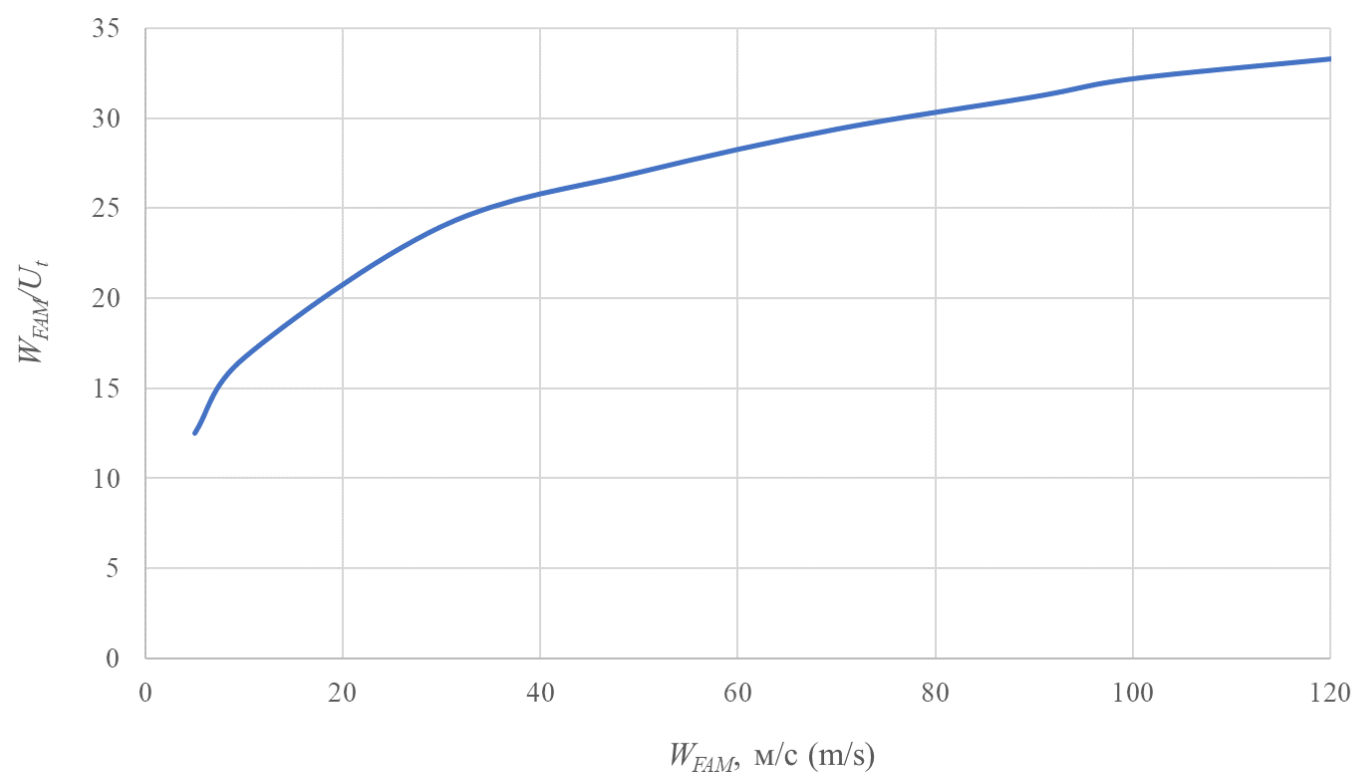

Рис. 5. Экспериментальная зависимость $W_{F A M} / U_{t}$ от среднерасходной скорости потока. ${ }^{11}$

${ }^{11}$ Appendix 1

Таблица $4^{12}$.

Теплогазодинамические параметры при численном моделировании низкотемпературного бедного горения ${ }^{13}$.

\begin{tabular}{|c|c|c|}
\hline $\begin{array}{c}\text { Название } \\
\text { (Denotation) }\end{array}$ & $\begin{array}{c}\text { Величина } \\
\text { (Value) }\end{array}$ & $\begin{array}{c}\text { Paзмерность } \\
\text { (Dimension) }\end{array}$ \\
\hline
\end{tabular}




\begin{tabular}{|c|c|c|}
\hline Диаметр КС (Combustion Chamber Diameter) & 0.140 & $\mathrm{M}(\mathrm{m})$ \\
\hline Давление в КС (Combustion Chamber Pressure) & 300000 & Па $(\mathrm{Pa})$ \\
\hline Интенсивность пламени (Flame Intensity) & $29 \ldots 70$ & $\mathrm{~K} \Gamma / \mathrm{c} \cdot \mathrm{M}^{3}\left(\mathrm{~kg} / \mathrm{s} \cdot \mathrm{m}^{3}\right)$ \\
\hline $\begin{array}{c}\text { Температура воздуха на входе в КС } \\
\text { (Air Temperature at the Combustion Chamber Inlet) }\end{array}$ & 800 & K \\
\hline $\begin{array}{c}\text { Температура топливного газа на входе в КС } \\
\text { (Fuel Temperature at the Combustion Chamber Inlet) }\end{array}$ & 800 & K \\
\hline $\begin{array}{l}\text { Коэффициент избытка воздуха } \\
\text { (Air Excess Ratio) }\end{array}$ & 3.0 & - \\
\hline $\begin{array}{c}\text { Температура на выходе из КС } \\
\text { (Air Temperature at the Combustion Chamber Outlet) }\end{array}$ & 1200 & K \\
\hline $\begin{array}{c}\text { Скорость газа на выходе из КС } \\
\text { (Air Velocity at the Combustion Chamber Outlet) }\end{array}$ & 98.7 & $\mathrm{M} / \mathrm{c}(\mathrm{m} / \mathrm{s})$ \\
\hline $\begin{array}{l}\text { Относительная расходонапряженность } \\
\text { (Relative Flow Rate) }\end{array}$ & $0.7 \cdot 10^{-4}$ & кг/c·H $(\mathrm{kg} / \mathrm{s} \cdot \mathrm{N})$ \\
\hline
\end{tabular}

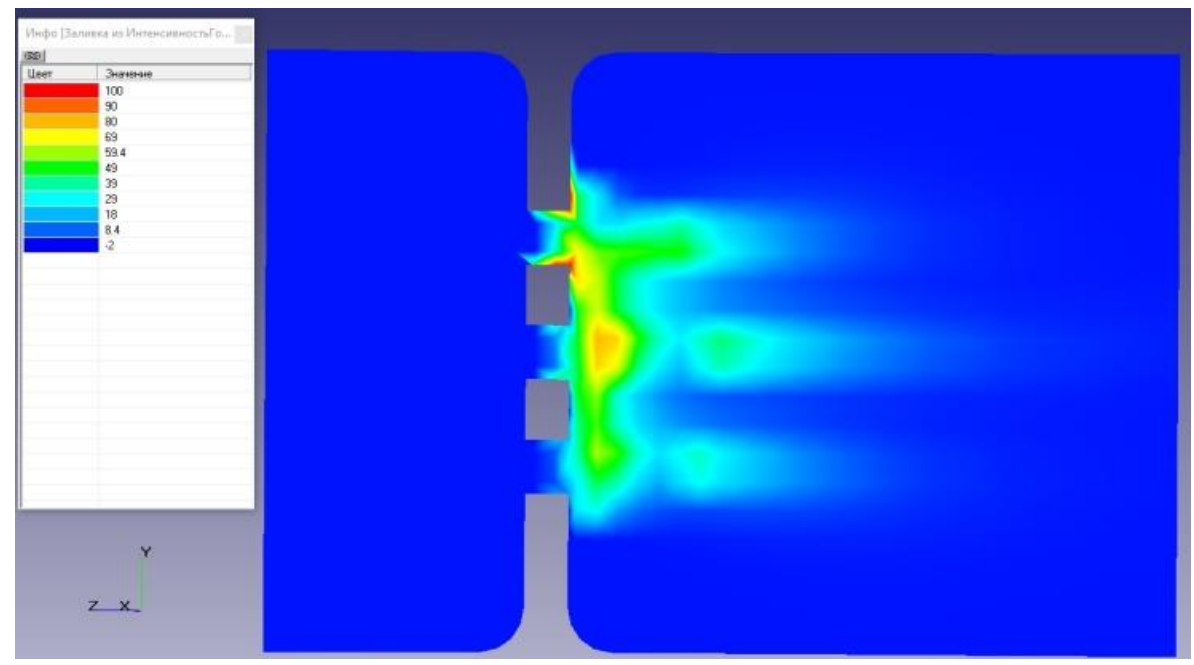

Рис. 6. Положение фронта пламени при низкотемпературном бедном горении в однозонной КС с внешним подогревом компонентов. ${ }^{14}$

По приведенной выше газодинамической модели получены условия устойчивого положения пламени для МГТЭУ с мощностями 200 и 400 кВт, при использовании турбокомпрессора со степенью сжатия 3.0, при реализации низкотемпературного бедного горения с внешним подогревом компонентов.

В таблице 6 приведены значения температуры ГВС $T_{F A м}$, выбранного коэффициента избытка воздуха $\alpha$, температуры продуктов сгорания на выходе из камеры $T_{C P}$, степени подогрева газа в камере $\theta$ и нормальные скорости горения $U_{n 0}$ при различных температу- pax компонентов на входе в камеру сгорания, которые являются общими для рассмотренного мощностного ряда МГТЭУ.

Перечисленные параметры выбраны в соответствии с графическими зависимостями на рисунках 2-4 и не зависят от мощностного ряда энергоустановок.

Газодинамические параметры ГВС и характеристики низкомтемпературного бедного горения получены для МГТЭУ с мощностями 200 и 400 кВт с использованием турбокомпрессора, степень сжатия которого равна 3.0.

Таблица $5^{15}$. 12,13,14 Appendix 1

глогазодинамические параметры при численном моделировании низкотемпературного бедного горения ${ }^{16}$.

\begin{tabular}{c|c|c|}
\hline $\begin{array}{c}\text { Название } \\
\text { (Denotation) }\end{array}$ & $\begin{array}{c}\text { Величина } \\
\text { (Value) }\end{array}$ & $\begin{array}{c}\text { Размерность } \\
\text { (Dimension) }\end{array}$ \\
\hline
\end{tabular}




\begin{tabular}{|c|c|c|}
\hline Диаметр КС (Combustion Chamber Diameter) & 0.140 & M (m) \\
\hline Давление в КС (Combustion Chamber Pressure) & 250000 & Па $(\mathrm{Pa})$ \\
\hline Интенсивность пламени (Flame Intensity) & $20.4 \ldots 34.5$ & $\kappa \Gamma / \mathrm{c} \cdot \mathrm{M}^{3}\left(\mathrm{~kg} / \mathrm{s} \cdot \mathrm{m}^{3}\right)$ \\
\hline $\begin{array}{c}\text { Температура воздуха на входе в КС } \\
\text { (Air Temperature at the Combustion Chamber Inlet) }\end{array}$ & 600 & K \\
\hline $\begin{array}{c}\text { Температура топливного газа на входе в КС } \\
\text { (Fuel Temperature at the Combustion Chamber Inlet) }\end{array}$ & 800 & K \\
\hline $\begin{array}{l}\text { Коэффициент избытка воздуха } \\
\text { (Air Excess Ratio) }\end{array}$ & 3.0 & - \\
\hline $\begin{array}{c}\text { Температура на выходе из КС } \\
\text { (Air Temperature at the Combustion Chamber Outlet) }\end{array}$ & 984 & K \\
\hline $\begin{array}{c}\text { Скорость газа на выходе из КС } \\
\text { (Air Velocity at the Combustion Chamber Outlet) }\end{array}$ & 84.5 & $\mathrm{M} / \mathrm{c}(\mathrm{m} / \mathrm{s})$ \\
\hline $\begin{array}{l}\text { Относительная расходонапряженность } \\
\text { (Relative Flow Rate) }\end{array}$ & $0.8 \cdot 10^{-4}$ & кг $/ \mathrm{c} \cdot \mathrm{H}(\mathrm{kg} / \mathrm{s} \cdot \mathrm{N})$ \\
\hline
\end{tabular}

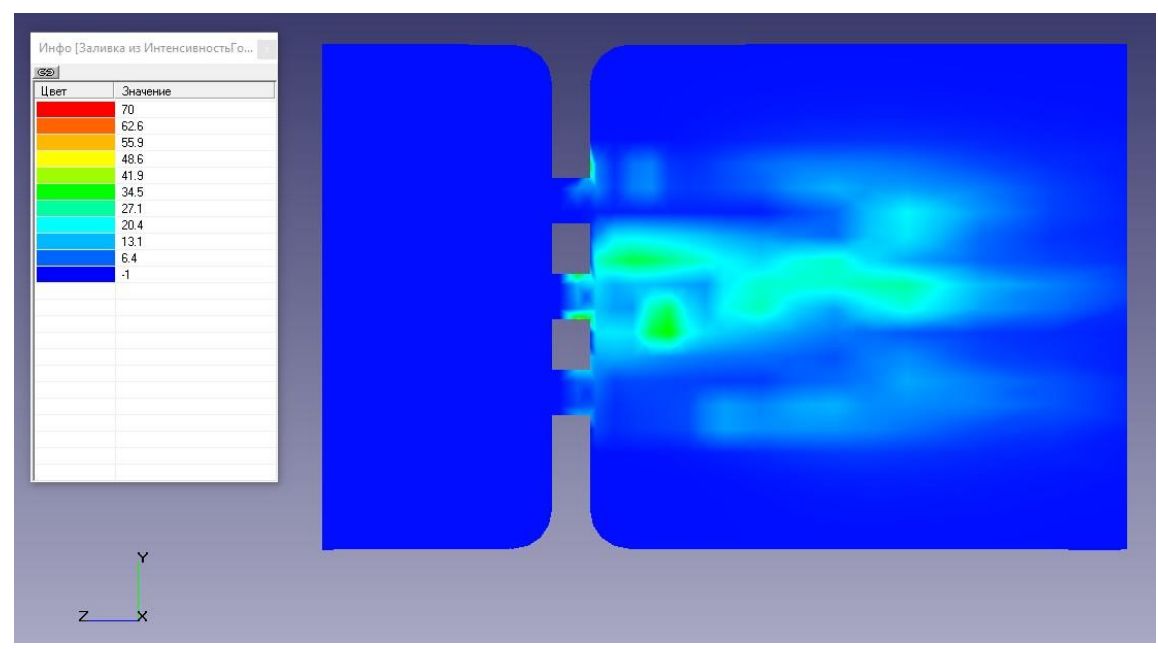

Рис. 7. Положение фронта пламени при низкотемпературном бедном горении в однозонной КС с внешним подогревом компонентов. ${ }^{17}$

При расчетно-экспериментальных исследованиях горения в потоке обычно рассматривают скорости ГВС на режимах проскока, устойчивого положения и срыва пламени в зависимости от коэффициента избытка воздуха или корреляционные зависимости с использованием критерия Дамклера. В данной работе области срыва, устойчивого положения и проскока пламени рассматриваются в зависимости от температуры подогрева компонентов и коэффициента избытка воздуха.

В таблице 7 приведены газодинамические параметры ГВС, скорости нормального и турбулентного горения для энергоустановки мощностью 200 кВт, для двух режимов работы КС.

На рисунке 8 для МГТЭУ-200 приведены графические зависимости $W_{F A M}=f\left(T_{F A M}\right)$ и $W_{F A M} / U_{t}=f\left(T_{F A M}\right)$ и показаны области срыва, устойчивого положения и проскока пламени.

При использовании одного и того же турбокомпрессора расходные характеристики МГТЭУ, следовательно, характеристики газового поката и турбулентного горения зависят от мощности МГТЭУ.

Таблица $6^{18}$. ${ }^{15,16,17}$ Appendix 1 раметры теплового состояния компонентов и газового потока ${ }^{19}$. 


\begin{tabular}{|c|c|c|c|c|c|c|c|}
\hline № & $T_{o x}^{\text {in }}, \mathrm{K}$ & $T_{f}^{\text {in }}, \mathrm{K}$ & $T_{\text {FAM }}, \mathrm{K}$ & $\alpha$ & $T_{C P}, \mathrm{~K}$ & $\theta$ & $U_{n 0}, \frac{\mathrm{M}}{\mathrm{c}}$ \\
\hline 1 & 400 & 600 & 411.5 & 3.0 & 1116 & 2.7 & 0.995 \\
\hline 2 & 500 & 800 & 515.3 & 4.0 & 1042 & 2.0 & 1.560 \\
\hline 3 & 600 & 800 & 610.0 & 4.0 & 1136 & 1.8 & 2.186 \\
\hline 4 & 700 & 1000 & 711.7 & 6.0 & 1045 & 1.4 & 2.975 \\
\hline 5 & 800 & 1000 & 808.3 & 5.5 & 1187 & 1.4 & 3.838 \\
\hline
\end{tabular}

Таблица $7^{20}$.

Характеристики газового потока и горения в КС МГТЭУ-200²1.

\begin{tabular}{|c|c|c|c|c|c|c|c|}
\hline & $\begin{array}{l}\text { давление г } \\
\text { д газа чере }\end{array}$ & $\begin{array}{l}\text { олезная мо } \\
\text { степень } \\
\mathrm{C} \text { (Pressure } \\
\text { гурбину (G }\end{array}$ & $\begin{array}{l}\text { оость }(\mathrm{N} \\
\text { атия }(\mathrm{Co} \\
\text { the Com } \\
\text { Flow Ra }\end{array}$ & $\begin{array}{l}\text { wer) } N \\
\text { ession F } \\
\text { ion Cha } \\
\text { arough }\end{array}$ & $\begin{array}{l}\text { io) } \varepsilon= \\
\text { ber) } P \\
\text { Turb }\end{array}$ & $\begin{array}{l}\mathrm{kW}) \\
297000 \text { Па }(\mathrm{P} \\
\dot{m}_{g}=1.417 \text { кг }\end{array}$ & $\mathrm{kg} / \mathrm{s})$. \\
\hline & & $\begin{array}{r}g_{k}=2.5 \\
d\end{array}$ & $\begin{array}{l}-4 \mathrm{~K} / \mathrm{c} \cdot \mathrm{H} \\
0.156 \mathrm{M}(\end{array}$ & $(s \cdot N)$ & $g_{k}=$ & $\begin{array}{c}8 \cdot 10^{-4} \mathrm{\kappa} / \mathrm{c} \cdot \mathrm{H} \\
d_{d}=0.276 \mathrm{M}\end{array}$ & $(\mathrm{s} \cdot \mathrm{N})$ \\
\hline$T_{F A M}, \mathrm{~K}$ & $U_{n}, \overline{\mathrm{c}}(\overline{\mathrm{s}})$ & $U_{t}, \frac{\mathrm{M}}{\mathrm{c}}\left(\frac{\mathrm{m}}{\mathrm{s}}\right)$ & $W_{F A M}, \frac{M}{c}$ & $\frac{W_{F A M}}{U_{t}}$ & $U_{t}, \frac{M}{c}$ & $W_{F A M}, \frac{\mathrm{M}}{\mathrm{c}}\left(\frac{\mathrm{m}}{\mathrm{s}}\right)$ & $\frac{W_{F A M}}{U_{t}}$ \\
\hline 411.5 & 0.264 & 2.201 & 29.685 & 13.487 & 1.191 & 9.484 & 7.963 \\
\hline 515.3 & 0.406 & 2.676 & 37.102 & 13.864 & 1.414 & 11.853 & 8.384 \\
\hline 610.0 & 0.262 & 2.684 & 43.920 & 16.362 & 1.190 & 14.031 & 11.793 \\
\hline 711.7 & 0.284 & 2.973 & 51.129 & 17.195 & 1.234 & 19.990 & 13.240 \\
\hline 808.3 & 0.216 & 3.221 & 58.093 & 18.034 & 1.245 & 18.559 & 14.911 \\
\hline
\end{tabular}
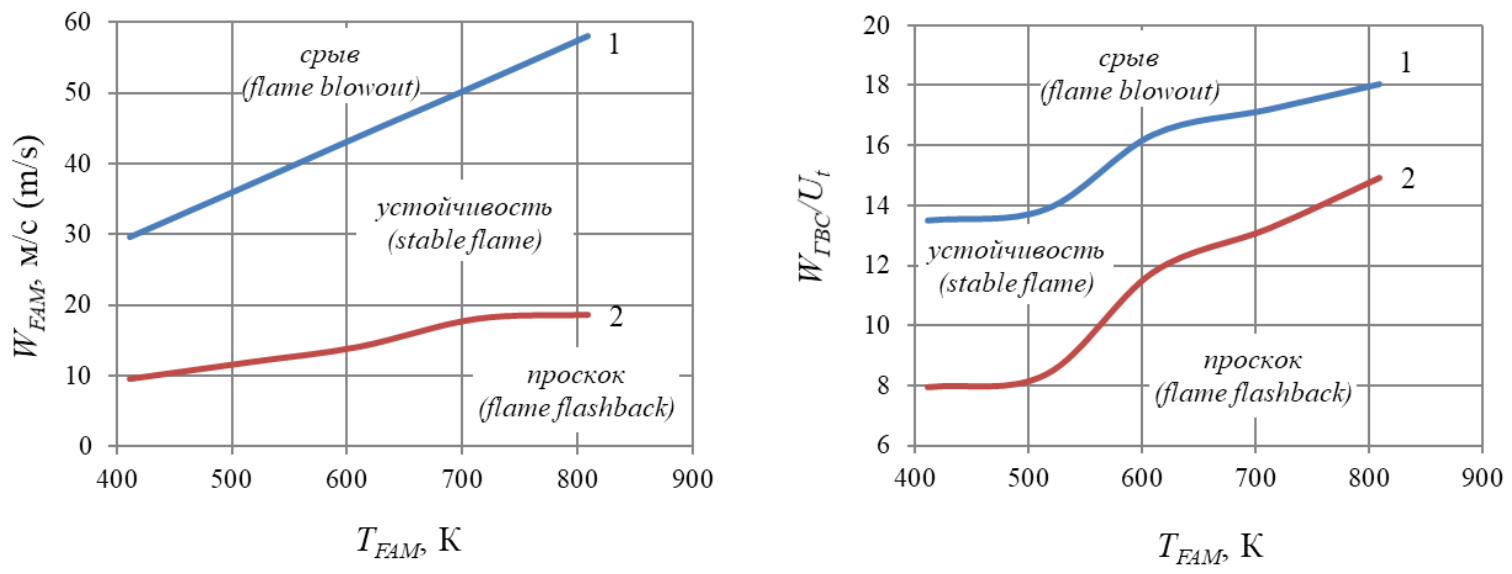

$1-d_{d}=0.156 \mathrm{M}(\mathrm{m}), 2-d_{d}=0.176 \mathrm{M}(\mathrm{m})$.

Рис. 8. Области срыва, устойчивого положения и проскока пламени для МГТЭУ -200. ${ }^{22}$

В таблице 8 приведены газодинамические параметры ГВС, скорости нормального и турбулентного горения для энергоустановки мощностью 400 кВт, для двух режимов работы КС.

18,19,20,21,22 Appendix 1
На рисунке 9 для МГТЭУ-400 приведены графические зависимости $W_{F A M}=f\left(T_{F A M}\right)$ и $W_{F A M} / U_{t}=f\left(T_{F A M}\right)$ и показаны области срыва, устойчивого положения и проскока пламени.

Сравнение расчетных данных для МГТЭУ с мощностями 200 и 400 кВт показывает, что 
при разных режимах работы, но при одинаковых значениях относительной расходонапря- женности, области срыва, устойчивого положения и проскока пламени совпадают.

Таблица $8^{23}$.

Характеристики газового потока и горения в КС МГТЭУ-400 24.

\begin{tabular}{|c|c|c|c|c|c|c|c|}
\hline \multicolumn{8}{|c|}{$\begin{array}{l}\text { Полезная мощность (Net Power) } N=300 \text { кВт }(\mathrm{kW}) ; \\
\text { степень сжатия (Compression Ratio) } \varepsilon=3.0 ; \\
\text { КС (Pressure at the Combustion Chamber) } P_{c h}=297000 \text { Па }(\mathrm{Pa}) ; \\
\text { з турбину (Gas Flow Rate Through the Turbine) } \dot{m}_{g}=2.835 \mathrm{\kappa} / \mathrm{c}(\mathrm{kg} / \mathrm{s}) \text {. }\end{array}$} \\
\hline \multirow{2}{*}{$T_{F A M}, \mathrm{~K}$} & \multirow{2}{*}{$U_{n}, \frac{\mathrm{M}}{\mathrm{c}}\left(\frac{\mathrm{m}}{\mathrm{s}}\right)$} & \multicolumn{3}{|c|}{$\begin{array}{c}g_{k}=2.5 \cdot 10^{-4} \mathrm{\kappa} / \mathrm{c} \cdot \mathrm{H}(\mathrm{kg} / \mathrm{s} \cdot \mathrm{N}) \\
d_{d}=0.22 \mathrm{M}(\mathrm{m})\end{array}$} & \multicolumn{3}{|c|}{$\begin{array}{c}g_{k}=0.8 \cdot 10^{-4} \mathrm{\kappa} / \mathrm{c} \cdot \mathrm{H}(\mathrm{kg} / \mathrm{s} \cdot \mathrm{N}) \\
d_{d}=0.39 \mathrm{M}(\mathrm{m})\end{array}$} \\
\hline & & $U_{t}, \frac{M}{c}$ & $W_{F A M}, \frac{\mathrm{M}}{\mathrm{c}}\left(\frac{\mathrm{m}}{\mathrm{s}}\right)$ & $\frac{W_{F A M}}{U_{t}}$ & $U_{t}, \frac{M}{c}$ & $W_{F A M}, \frac{\mathrm{M}}{\mathrm{c}}\left(\frac{\mathrm{m}}{\mathrm{s}}\right)$ & $\frac{W_{F A M}}{U_{t}}$ \\
\hline 411.5 & 0.264 & 2.202 & 29.711 & 13.490 & 1.191 & 9.488 & 7.965 \\
\hline 515.3 & 0.406 & 2.652 & 36.610 & 13.807 & 1.406 & 11.691 & 8.317 \\
\hline 610.0 & 0.262 & 2.686 & 43.958 & 16.365 & 1.190 & 14.037 & 11.795 \\
\hline 711.7 & 0.284 & 2.976 & 51.173 & 17.197 & 1.234 & 16.341 & 13.242 \\
\hline 808.3 & 0.216 & 3.224 & 58.144 & 18.035 & 1.245 & 18.567 & 14.912 \\
\hline
\end{tabular}

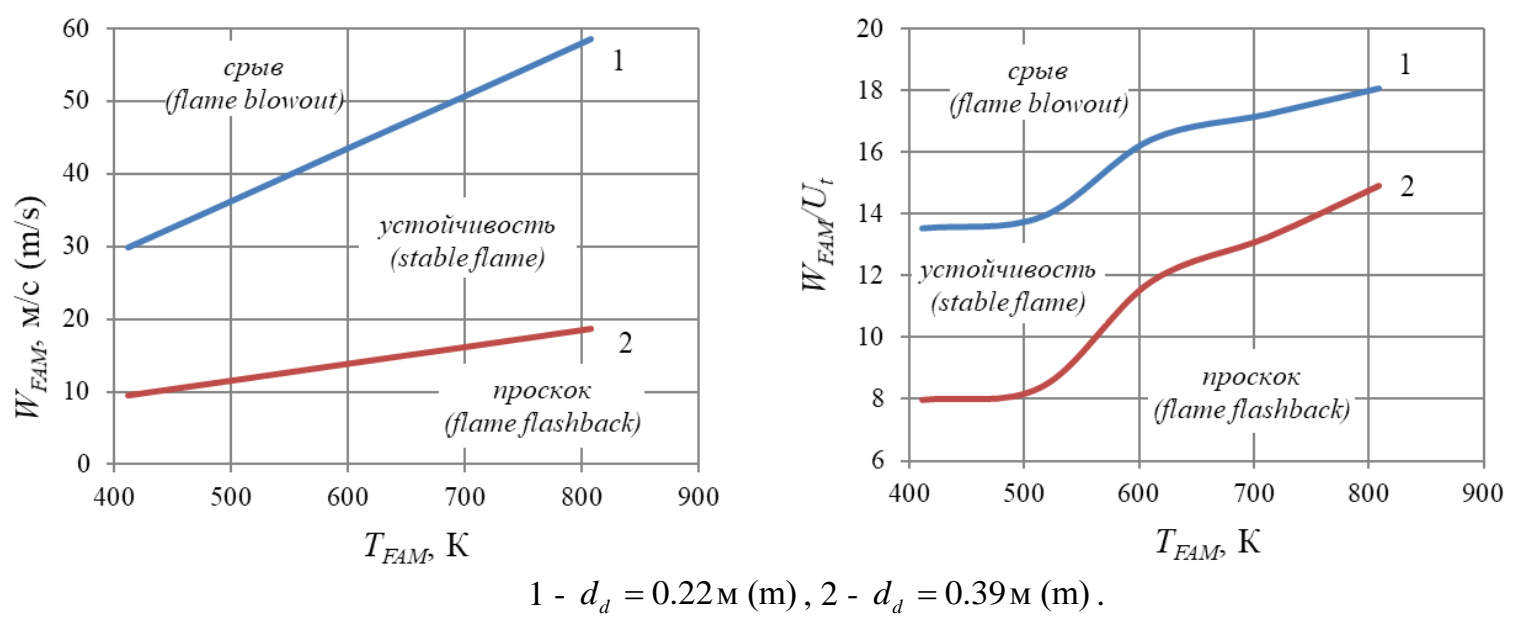

Рис. 9. Области срыва, устойчивого положения и проскока пламени для МГТЭУ-400.

\section{ЗАКЛЮЧЕНИЕ}

Таким образом, проведенные исследования позволяют сформулировать следующие выводы:

- влияние внешнего подогрева компонентов заключается в расширении предела низкотемпературного бедного горения;

- обработка опубликованных экспериментальных данных и численное моделирование низкотемпературного бедного горения с внешним подогревом компонентов позволили определить диапазон относительной 23,24,25 Appendix 1 зсти $g_{k}=(0.3 \ldots 3.5) \cdot 10^{-4}$
кг/с·H, при котором обеспечивается устойчивое положение пламени;

- использование относительной расходонапряженности в качестве обобщенной характеристики позволяет оперативно определить условия стабильного положения пламени в камерах сгорания микрогазотурбинных энергоустановок;

- приведенные примеры определения режимных и геометрических параметров однозонной неохлаждаемой КС по предложенной методике показывают возможность организации низкотемпературного бедного горения с внешним подогревом компонентов. 


\section{APPENDIX 1 (ПРИЛОЖЕНИЕ 1)}

${ }^{1}$ Fig. 1. Schematic diagram of MGTPP with external heating of components.

${ }^{2,3}$ Table 1. Lower combustion limits when heating components.

${ }^{4}$ Fig. 2. Lower combustion limits when heating components.

${ }^{5,6}$ Table 2. Fuel-air mixture temperature when heating components.

${ }^{7}$ Fig. 3. Fuel-air mixture temperature when heating components.

${ }^{8,9}$ Table 3. Combustion products temperature at the lower limit of combustion.

${ }^{10}$ Fig. 4. Region of low-temperature combustion of MGTPP.

${ }^{11}$ Fig. 5. Experimental dependence of $W_{\mathrm{FAM}} / U_{t}$ on the average flow rate.

${ }^{12,13}$ Table 4. Thermal and gas-dynamic parameters for numerical modeling of low-temperature lean combustion.

${ }^{14}$ Fig. 6. Flame front position at low-temperature lean combustion in a single-zone combustor with external heating of components.

${ }^{15,16}$ Table 5. Thermal and gas-dynamic parameters for numerical modeling of low-temperature lean combustion.

${ }^{17}$ Fig. 7. Position of the flame front at lowtemperature lean combustion in a single-zone combustion chamber with external heating of components.

${ }^{18,19}$ Table 6. Parameters of thermal state of components and gas flow.

${ }^{20,21}$ Table 7. Characteristics of the gas flow and combustion in the combustion chamber of MGTPP-200.

${ }^{22}$ Fig. 8. Areas of stall, stable position and flame breakthrough for MGTPP-200.

${ }^{23,24}$ Table 8. Characteristics of the gas flow and combustion in the MGTPP-400 combustion chamber.

${ }^{25}$ Fig. 9. Areas of stall, stable position and flame breakthrough for MGTPP-400.

\section{Литература (References)}

[1] Kumar S., Paul P.J., Mukunda H.S. Studies on a new high-intensity low-emission burner. Proceedings of the Combustion Institute, 2002, vol. 29(1), pp. 1131-1137, doi: 10.1016/S15407489(02)80143-2.

[2] Wierzba I., Kilchyk V. Flammability limits of hydrogen-carbon monoxide mixtures at moderately elevated temperatures. International Journal of Hydrogen Energy, 2001, vol. 26(6), pp. 639-643, doi: 10.1016/S03603199(00)00114-2.

[3] Gibbon H.J., Wainwright J., Rogers R.L. Experimental determination of flammability limits of solvents at elevated temperatures and pressures. In Institution of Chemical Engineers Symposium Series, 1994, no. 134, pp. 1-12.

[4] Li Z., Gong M., Sun E., Wu J., Zhou Y. Effect of low temperature on the flammability limits of methane/nitrogen mixtures. Energy, 2011, vol. 36(9), pp. 5521-5524, doi: 10.1016/j.energy.2011.07.023.

[5] Ale B.B., Wierzba I. The flammability limits of hydrogen and methane in air at moderately elevated temperatures. IECEC-97 Proceedings of the Thirty-Second Intersociety Energy Conversion Engineering Conference (Cat. No.97CH6203), 1997, vol. 2, pp. 938-943, doi: 10.1109/IECEC.1997.661895.

[6] Bolshova T.A., Bunev V.A., Knyazkov D.A., Korobeinichev O.P., Chernov A.A., Shmakov A.G., Yakimov S.A. Dependence of the lower flammability limit on the initial temperature. Combustion, Explosion, and Shock Waves, 2012, vol. 48(2), pp. 125-129, doi: 10.1134/S0010508212020013.

[7] Wang T., Luo Z., Wen H., Cheng F., Deng J., Zhao J., Guo Z., Lin J., Kang K., Wang W. Effects of flammable gases on the explosion characteristics of $\mathrm{CH} 4$ in air. Journal of Loss Prevention in the Process Industries, 2017, vol. 49, part B, pp. 183-190, doi: 10.1016/j.jlp.2017.06.018.

[8] Vanderstraeten B., Tuerlinckx D., Berghmans J., Vliegen S., Van't Oost E., Smit B. Experimental study of the pressure and temperature dependence on the upper flammability limit of methane/air mixtures. Journal of Hazardous Materials, 1997, vol. 56(3), pp. 237-246, doi: 10.1016/S0304-3894(97)00045-9.

[9] Kondo S., Takahashi A., Takizawa K., Tokuhashi $\mathrm{K}$. On the pressure dependence of flammability limits of $\mathrm{CH} 2=\mathrm{CFCF} 3, \mathrm{CH} 2 \mathrm{~F} 2$ and methane. Fire Safety Journal, 2011, vol. 46(5), pp. 289293, doi: 10.1016/j.firesaf.2011.03.005.

[10] Xiouris C., Ye T., Jayachandran J., Egolfopoulos F.N. Laminar flame speeds under engine-relevant conditions: uncertainty quantification and minimization in spherically expanding flame experiments. Combustion and Flame, 2016, vol. 163, pp. 270-283, doi: 10.1016/j.combustflame.2015.10.003.

[11] Akram M., Kumar S. Experimental studies on dynamics of methane-air pre-mixed flame in meso-scale diverging channels. Combustion and Flame, 2011, vol. 158(5), pp. 915-924, doi: 10.1016/j.combustflame.2011.02.011.

[12]Zhao Z., Kazakov A., Li J., Dryer F.L. The initial temperature and $\mathrm{N}-2$ dilution effect on the laminar flame speed of propane/air. Combustion Science and Technology, 2004, vol. 176(10), pp. 1705-23, doi: 10.1080/00102200490487553.

[13] Tang C., Zheng J., Huang Z., Wang J. Study on nitrogen diluted propane-air premixed flames at elevated pressures and temperatures. Energy Conversion and Management, 2010, vol. 51(2), 
pp.

288-295,

10.1016/j.enconman.2009.09.024.

[14] Galmiche B., Halter F., Foucher F. Effects of high pressure, high temperature and dilution on laminar burning velocities and Markstein lengths of iso-octane/air mixtures. Combustion and Flame, 2012, vol. 159(11), pp. 3286-3299, doi: 10.1016/j.combustflame.2012.06.008.

[15]Liao S.Y., Jiang D.M., Huang Z.H., Shen W.D., Yuan C., Cheng Q. Laminar burning velocities for mixtures of methanol and air at elevated temperatures. Energy Conversion and Management, 2007, vol. 48(3), pp. 857-863, doi: 10.1016/j.enconman.2006.08.017.

[16] Iijima T., Takeno T. Effects of temperature and pressure on burning velocity. Combustion and Flame, 1986, vol. 65(1), pp. 35-43, doi: 10.1016/0010-2180(86)90070-2.

[17] Akram M., Kishore V.R., Kumar S. Laminar burning velocity of propane/CO2/N2-Air mixtures at elevated temperatures. Energy Fuels, 2012, vol. 26(9), pp. 5509-5518, doi: 10.1021/ef301000k.

[18] Akram M., Kumar S. Measurement of laminar burning velocity of liquified petrolium gas air mixtures at elevated temperatures. Energy Fuels, 2012, vol. 26(6), pp. 3267-3274, doi: 10.1021/ef300101n.

[19] Rau F., Hartl S., Voss S., Still M., Hasse C., Trimis D. Laminar burning velocity measurements using the Heat Flux method and numerical predictions of iso-octane/ethanol blends for different preheat temperatures. Fuel, 2015, vol. 140, pp. 10-16, doi: 10.1016/j.fuel.2014.09.059.

[20]Akram M., Kumar S., Saxena P. Experimental and computational determination of laminar burning velocity of Liquefied Petroleum Gas-air

\section{Сведения об авторах.}

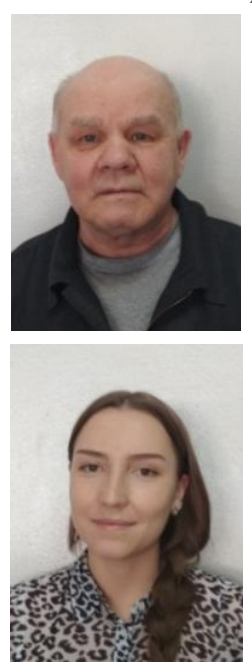

Бачев Николай Леонидович

- к.т.н., доцент кафедры «Ракетно-космическая техника и энергетические системы» ПНИПУ. Область научных интересов: утилизационные газотурбинные установки. E-mail: bn154@yandex.ru

Шилова Алена Алексеевна инженер кафедры «Ракетнокосмическая техника и энергетические системы» ПНИПУ Область научных интересов: рабочие процессы в КС ЭУ. E-mail: alyona1203@gmail.com mixtures at elevated temperatures. Journal of Engineering for Gas Turbines and Power, 2013, vol. 135(9), pp. 091501-1-091501-5, doi: 10.1115/1.4024798.

[21] Natarajan J., Kochar Y., Lieuwen T., Seitzman J. Pressure and preheat dependence of laminar flame speeds of $\mathrm{H} 2 / \mathrm{CO} / \mathrm{CO} 2 / \mathrm{O} 2 / \mathrm{He}$ mixtures. Proceedings of the Combustion Institute, 2009, vol. 32(1), pp. 1261-1268, doi: 10.1016/j.proci.2008.06.110.

[22] Boushaki T., Dhue Y., Selle L., Ferret B., Poinsot T. Effects of hydrogen and steam addition on laminar burning velocity of methaneair premixed flame: Experimental and numerical analysis. International Journal of Hydrogen Energy, 2012, vol. 37(11), pp. 9412-9422, doi: 10.1016/j.ijhydene.2012.03.037.

[23] Kuznetsov M., Kobelt S., Grune J., Jordan T. Flammability limits and laminar flame speed of hydrogen-air mixtures at sub-atmospheric pressures. International Journal of Hydrogen Energy, 2012, vol. 37(22), pp. 17580-17588, doi: 10.1016/j.ijhydene.2012.05.049.

[24] Clavin P. Dynamic behavior of premixed flame fronts in laminar and turbulent flows. Progress in Energy and Combustion Science, 1985, vol. 11(1), pp. 1-59, doi: 10.1016/03601285(85)90012-7.

[25] Karlovitz B., Denniston D.W., Knapschaefe D.H., Wells F.E. Studies on Turbulent flames: A. Flame Propagation Across velocity gradients B. turbulence Measurement in flames. Symposium (International) on Combustion, 1953, vol. 4(1), pp. 613-620, doi: 10.1016/S00820784(53)80082-2.

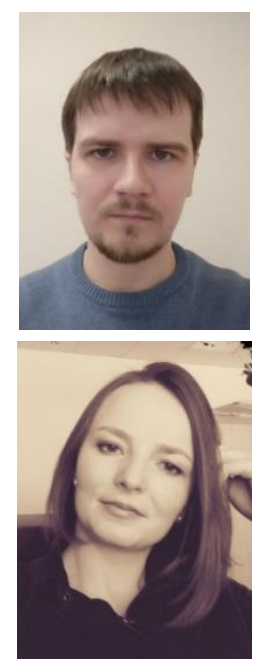

Матюнин Олег Олегович старший преподаватель кафедры «Ракетно-космическая техника и энергетические системы» ПНИПУ. Область научных интересов: численное моделирование рабочих процессов в ЭУ.

E-mail: matoleg@gmail.com

Бетинская Оксана Андреевна - к.т.н, доцент кафедры «Ракетно-космическая техника и энергетические системы» ПНИПУ. Область научных интересов: турбомашины и комбинированные ЭУ.

E-mail: oksanochka_zueva@mail.ru 